\title{
Emergency Cardiopulmonary Resuscitation of Out- of Hospital Cardiac Arrest: Why Should we Care
}

\author{
Luxiao Huang \\ Hangzhou First People's Hospital \\ Jinyao Chen \\ Hangzhou Emergency Center \\ Baojun Yu \\ Xinchang County People's Hospital \\ Chunfu Tang \\ Hangzhou Emergency Center \\ Xiaoliang Ma ( $\nabla$ zhuoan342161caoh@163.com ) \\ Hangzhou First People's Hospital
}

\section{Research Article}

Keywords: cardiopulmonary resuscitation, cardiac arrest, emergency, treatment, care

Posted Date: August 17th, 2021

DOI: https://doi.org/10.21203/rs.3.rs-778098/v1

License: (c) (i) This work is licensed under a Creative Commons Attribution 4.0 International License.

Read Full License 


\section{Abstract}

Background: Cardiopulmonary resuscitation (CPR) plays an essential role in the treatment of sudden cardiac arrest (SCA), we aimed to evaluate the influencing factors on the effects of CPR in patients with SCA, to provide insights into the management of SCA.

Methods: Patients who underwent CPR in the emergency department of our hospital from January 1 , 2019 to June 30, 2021 were selected. We collected and analyzed the clinical characteristics of CPR patients. Logistic regression analyses were conducted to identify the risk factors of CPR failure.

Results: A total of 308 CPR patients were included, the incidence of CPR success was $35.71 \%$. There were significant differences in the age, time to the start of CPR, the type of heart rhythm in the first monitoring, duration of CPR and cumulative adrenaline dosage between CPR success and failure group (all $P<0.05$ ). No significant differences in the gender, cause of cardiac arrest and ventilation methods were found (all $P>0.05)$. Logistic regression analyses indicated that age $\geq 65 y(O R 2.132,95 \mathrm{Cl} \% 1.127 \sim 4.334)$, time to the start of $C P R \geq 12 \min (O R 2.503,95 \mathrm{Cl} \% 1.015 \sim 3.583)$, unable to defibrillation(OR1.856, 95Cl\%1.107 3.031), duration of $\mathrm{CPR} \geq 40 \mathrm{~min}(\mathrm{OR} 2.162,95 \mathrm{Cl} \% 1.242 \sim 4.178)$, cumulative adrenaline dosage $\geq 6 \mathrm{mg}(\mathrm{OR} 1.627$, $95 \mathrm{Cl} \% 1.151 \sim 2.472)$ were the independent risk factors of CPR failure(all $\mathrm{P}<0.05)$.

Conclusions: The success and failure of CPR are affected by many factors. Early and effective interventions should be taken for these influencing factors in clinical practice. Due to the limitation of sample size, future large-sample and multi-center studies need to further explore the relevant influencing factors of CPR.

\section{Background}

Sudden cardiac arrest (SCA) refers to the sudden cessation of cardiac activity accompanied by hemodynamic disorders, usually caused by persistent ventricular tachycardia (VT)/ventricular fibrillation (VF)[1]. Most of these events occur in patients with organic heart disease especially coronary heart disease) that may not have been diagnosed before SCA[2]. In the rescue of SCA patients, cardiopulmonary resuscitation (CPR) plays a vital role, and chest compression combined with mouth-tomouth breathing is the basis of modern CPR[3]. Although CPR, defibrillation and other advanced resuscitation techniques continue to develop, the survival rate of cardiac arrest is still very low $[4,5]$. Therefore, how to improve the effects and safety of CPR is essential to the prognosis of patients with SCA.

Cardiac arrest is a kind of clinical emergency and critical illness, the success of CPR is closely related to the cause of the cardiac arrest, the time of the arrest, and the correct first aid measures[6, 7]. With the widespread clinical application of CPR, patients with SCA have been effectively treated, but the success rate of resuscitation is still low[8]. Studies[9, 10] have shown that the success rate of resuscitation in patients with cardiac arrest in different locations is also different, only $6.0-10.8 \%$ of patients with out-ofhospital SCA can survive, while about $25.8 \%$ of patients with in-hospital cardiac arrest can survive and 
discharge. Therefore, improving the success rate of CPR is still one of the major challenges of clinical work. To this end, we took CPR patients in the emergency department of our hospital as the research population, we retrospectively analyzed the clinical characteristics of patients with SCA in order to analyze the factors affecting the success of PCR, and to provide reference for the rescue of critically ill patients.

\section{Methods}

\section{Ethical approval}

In this study, all methods were performed in accordance with the relevant guidelines and regulations. This present study protocol had been checked and approved by the ethical committee of Hangzhou First People's Hospital(approval number:ED20180049M), and written informed consents had been obtained from the relatives of included patients.

\section{Patients}

In this study, patients who underwent CPR in the emergency department of our hospital from January 1 , 2019 to June 30, 2021 were selected as the research populations. The inclusion criteria were as following: (1)patients with SCA; (2) patients underwent PCR in our department; (3)patients with age $>10$ years old; (4) The relatives of included patients agree to participant in this study and signed the written informed consents. The exclusion criteria were as following: (1) family members who gave up rescue and refused to perform PCR; (2) patients with incomplete or missing data on the treatment during hospitalization.

\section{CPR}

The CPR program referred to the American Heart Association(AHA) cardiopulmonary resuscitation and cardiovascular first aid guidelines[11, 12], specifically as follows: (1) we performed chest compressions at a rate of 100 120 times/min, and kept the depth of chest compressions at 5 6 cm; (2) The airway was opened at the same time as the chest compressions were started. A balloon mask was usually used to maintain sufficient oxygen supply. If necessary, tracheal intubation would be performed. The ventilation rate was maintained at 10 breaths per minute; (3) For patients with ventricular fibrillation or pulseless ventricular tachycardia detected at the beginning or midway would receive electrical defibrillation immediately; (4) For patients who did not need electrical defibrillation, epinephrine would be used as soon as possible, $1 \mathrm{mg}$ each time, An intravenous injection is given in 3 to 5 minutes intervals; (5) Patients with cardiac arrest caused by different reasons would be treated as soon as possible to remove the risk factors. After completing 5 cycles, we evaluated the patient's condition. The criteria for successful CPR were: (1) palpable aortic pulsation or audible heart sounds; (2) measurable blood pressure, blood 
pressure maintained above $90 / 60 \mathrm{mmHg}$, and it could be maintained for 24 hours (3) The patient regained his light reflex.

\section{Data collection}

We collected the patient's name, gender, age, time of cardiac arrest, place of onset, main cause of cardiac arrest, type of heart rhythm monitored for the first time, whether to receive electrical defibrillation, whether to accept tracheal intubation, cumulative epinephrine dosage, total duration of CPR according to the registration content of Utstein model registration form.

\section{Statistical method}

We used SPSS25.0 statistical software to analyze the collected data. All measurement data are first tested for normality. Data conforming to the normal distribution were expressed as mean \pm standard deviation, and independent sample t test is used for comparison between groups; count data was expressed as frequency or percentage, and comparison between groups was used $\chi 2$ test. Logistic regression analyses were conducted to identify the risk factors of CPR failure. The tests were all twosided, and $\mathrm{P}<0.05$ indicated that that the difference was statistically significant.

\section{Results}

\section{The characteristics of included patients}

A total of 308 CPR patients were enrolled in this study, including 185 males and 123 females. As presented in Figure 1, the average age was (66.34 16.62$)$ years ole, of which 71-80 years old had the largest number of patient, followed by 61-70 years old. And the main causes of cardiac arrest in patients with CPR were presented in Table 1.

Table 1

The main causes of cardiac arrest in patients with $\mathrm{CPR}(\mathrm{n}=308)$ 


\begin{tabular}{|lll|}
\hline Causes & Cases & Percentage \\
\hline Acute myocardial infarction & 115 & $37.34 \%$ \\
\hline Unclear causes & 57 & $18.51 \%$ \\
\hline Respiratory depression & 35 & $11.36 \%$ \\
\hline Disorders of electrolyte metabolism & 30 & $9.74 \%$ \\
\hline Severe hypotension & 25 & $8.12 \%$ \\
\hline Sepsis & 18 & $5.84 \%$ \\
\hline Poisoning & 14 & $4.55 \%$ \\
\hline Severe trauma & 10 & $3.25 \%$ \\
\hline Others & 4 & $1.30 \%$ \\
\hline
\end{tabular}

Of the included 308 SCA patients, 110 patients had the survived from the CPR, the incidence of CPR success was $35.71 \%$. As indicated in Table 2, there were significant differences in the age, time to the start of CPR, the type of heart rhythm in the first monitoring, duration of CPR and cumulative adrenaline dosage between CPR success and failure group (all $\mathrm{P}<0.05$ ). No significant differences in the gender, cause of cardiac arrest and ventilation methods were found (all $P>0.05$ ).

Table 2

the characteristics of included patients 


\begin{tabular}{|c|c|c|c|c|}
\hline Items & $\begin{array}{l}\text { CPR success } \\
\text { group }(n=110)\end{array}$ & $\begin{array}{l}\text { CPR failure } \\
\text { group(n=198) }\end{array}$ & $t / c^{2}$ & $\mathrm{P}$ \\
\hline Male/female & $69 / 41$ & 116/82 & 1.295 & 0.078 \\
\hline Age & $55.34 \pm 10.77$ & $73.05 \pm 12.84$ & 13.122 & 0.005 \\
\hline Cause of cardiac arrest & & & 1.626 & 0.053 \\
\hline Cardiac associated & $54(49 / 09 \%)$ & $61(30.81 \%)$ & & \\
\hline Non-cardiac associated & $56(50.91 \%)$ & 137(69.19\%) & & \\
\hline Time to the start of CPR(min) & $9.07 \pm 1.29$ & $15.44 \pm 3.31$ & 2.198 & 0.027 \\
\hline $\begin{array}{l}\text { The type of heart rhythm in the } \\
\text { first monitoring }\end{array}$ & & & 1.604 & 0.022 \\
\hline Able to defibrillation & $48(43.64 \%)$ & $35(17.68 \%)$ & & \\
\hline Unable to defibrillation & $62(56.36 \%)$ & $163(82.32 \%)$ & & \\
\hline Ventilation method & & & 1.459 & 0.086 \\
\hline Tracheal intubation & $81(73.64 \%)$ & $132(66.67 \%)$ & & \\
\hline Balloon mask & $29(26.36 \%)$ & $66(33.33 \%)$ & & \\
\hline Duration of CPR $₫ \min \rrbracket$ & $33.04 \pm 6.09$ & $46.32 \pm 7.57$ & 10.478 & 0.013 \\
\hline $\begin{array}{l}\text { Cumulative adrenaline dosage } \\
\text { (mg) }\end{array}$ & $4.38 \pm 2.61$ & $8.16 \pm 2.99$ & 2.129 & 0.025 \\
\hline
\end{tabular}

\section{The risk factors of CPR failure}

The variable assignments of multivariate logistic regression were showed in Table 3. As presented in Table 4, logistic regression analyses indicated that age $\geq 65 \mathrm{y}(\mathrm{OR} 2.132,95 \mathrm{Cl} \% 1.127 \sim 4.334)$, time to the start of $\mathrm{CPR} \geq 12 \mathrm{~min}(\mathrm{OR} 2.503,95 \mathrm{Cl} \% 1.015 \sim 3.583)$, unable to defibrillation(OR1.856, 95Cl\%1.107 3.031), duration of $\mathrm{CPR} \geq 40 \mathrm{~min}(\mathrm{OR} 2.162,95 \mathrm{Cl} \% 1.242 \sim 4.178)$, cumulative adrenaline dosage $\geq 6 \mathrm{mg}$ (OR1.627, $95 \mathrm{Cl} \% 1.151 \sim 2.472)$ were the independent risk factors of CPR failure(all $\mathrm{P}<0.05)$.

Table 3

The variable assignment of multivariate logistic regression 


\begin{tabular}{|lll|}
\hline Factors & Variables & Assignment \\
\hline CPR failure & Y & Yes=1, no=2 \\
\hline Age $(\mathrm{y})$ & $\mathrm{X}_{1}$ & $\geq 65=1,<65=2$ \\
\hline Time to the start of CPR(min) & $X_{2}$ & $\geq 12=1,<12=2$ \\
\hline $\begin{array}{l}\text { The type of heart rhythm in the first } \\
\text { monitoring }\end{array}$ & $X_{3}$ & $\begin{array}{l}\text { Unable to defibrillation=1, able to } \\
\text { defibrillation }=2\end{array}$ \\
\hline Duration of CPR(min) & $X_{4}$ & $\geq 40=1,<40=2$ \\
Cumulative adrenaline dosage $(\mathrm{mg})$ & $X_{5}$ & $\geq 6=1,<6=2$ \\
\hline
\end{tabular}

Table 4

The logistic regression analysis on the risk factors of CPR failure

\begin{tabular}{|llllll|}
\hline Variables & $\beta$ & $S^{\prime} x$ & OR & $95 \% \mathrm{Cl}$ & $\mathrm{p}$ \\
\hline Age $\geq 65 \mathrm{y}$ & 0.123 & 0.203 & 2.132 & $1.127 \sim 4.334$ & 0.011 \\
\hline Time to the start of CPR $\geq 12 \mathrm{~min}$ & 0.102 & 0.132 & 2.503 & $1.015 \sim 3.583$ & 0.025 \\
\hline Unable to defibrillation & 0.114 & 0.102 & 1.856 & $1.107 \sim 3.031$ & 0.043 \\
\hline Duration of CPR $\geq 40 \mathrm{~min}$ & 0.126 & 0.117 & 2.162 & $1.242 \sim 4.178$ & 0.021 \\
\hline Cumulative adrenaline dosage $\geq 6 \mathrm{mg}$ & 0.115 & 0.142 & 1.627 & $1.151 \sim 2.472$ & 0.018 \\
\hline
\end{tabular}

\section{Discussion}

Cardiac arrest is one of the most critical and dangerous clinical conditions. Although the level of medical treatment has made great progress in recent decades, the prognosis of cardiac arrest is still poor[13]. A report[14] analyzed the outcomes of more than 12,000 patients, these patients were the patients treated by Emergency Medical Service (EMS) staff in Seattle, USA during the 24 years, the patients treated in 1998-2001 and the patients treated in 1977-1981 were compared, the ratio of survival to discharge did not improve significantly (15.7\% vs $17.5 \%)$. The United States Improved Survival Cardiac Arrest Registry (CARES) registry study prospectively included 70,027 American patients with out-of-hospital SCA from 2005 to 2012 , and found that the discharge survival rate increased significantly from $5.7 \%$ in 2005 to $20128.3 \%$ of the year[15]. The success rate of CPR in our study was $35.71 \%$. All patients in this study treated in the department of emergency of our hospital and received timely and correct treatment. Therefore, the success rate of CPR is higher than that of previous reports[16-18]. And we have found that age $\geq 65 y$, time to the start of $C P R \geq 12 \mathrm{~min}$, unable to defibrillation, duration of $C P R \geq 40 \mathrm{~min}$, cumulative 
adrenaline dosage $\geq 6 \mathrm{mg}$ are the independent risk factors of CPR failure, early alert and preventions are needed for those patients.

The ratio of men to women in SCA patients in this preset study is 1.46:1, but the univariate analysis showed that gender had no significant effect on the success rate of cardiopulmonary resuscitation. Age is an independent factor affecting the success rate of CPR. Younger patients have a higher success rate of CPR. This is consistent with the results of previous related studies[19-21]. The reason may be that most elderly patients have circulatory and respiratory diseases, and the body function is poor[22]. Once cardiac arrest occurs, the tolerance of various organs to ischemia and hypoxia is poor[23]. For patients with emergency cardiac arrest, medical staff can effectively monitor their initial heart rhythm type. The results of this article have found that the success rate of CPR is higher in patients with defibrillating heart rhythm than in patients with non-defibrillating heart rhythm, and the initial heart rhythm type is the influencing factor of CPR success. Studies[24, 25] have found that in patients with cardiac arrest in the hospital, if the initial heart rhythm type is a defibrillating heart rhythm, their CPR success rate, survival rate after discharge, and neurological recovery at discharge are all improved than those who cannot defibrillate, which is in line with the findings of our study. The reason may be that when the initial heart rhythm is ventricular fibrillation or ventricular tachycardia, the heart is in a weak and irregular contraction state, and there is weak tissue perfusion in the body, so the effect of CPR is better[20, 26].

In the process of CPR, chest compressions are the primary rescue method, but the choice of ventilation methods is still controversial. In this study, compared with balloon masks, tracheal intubation has no positive effect on the success rate of cardiopulmonary resuscitation. Previous study[27] has pointed out that compared with balloon mask-assisted ventilation, the establishment of advanced airway will increase the adverse effect on the long-term prognosis. This may be because cardiac arrest patients are usually accompanied by irritability, vomiting, difficult tracheal intubation, longer length of intubation process[28-30]. Besides, it is inevitable to terminate the heart compression during the intubation process, so that the coronary artery blood perfusion is interrupted for too long[31, 32]. However, there are also reports[33,34] suggesting that for patients with pulmonary disease, tracheal intubation may be a favorable factor for the success of CPR, so it is necessary to choose a suitable ventilation method according to the specific situation.

Regarding the dose of epinephrine used, the CRP group had a larger amount of epinephrine, but it is not clear whether the prolonged resuscitation time caused the larger epinephrine use, or whether the large amount of epinephrine used adversely affect the resuscitation process[35]. Studies[36-38] have shown that adrenaline can increase myocardial oxygen consumption and reduce blood perfusion of other organs, which will adversely affect the long-term survival rate of discharged patients and the recovery of neurological function. Therefore, further research is needed to clarify the dose and timing of epinephrine in the CPR process.

\section{Conclusions}


In summary, cardiogenic disease is the main cause of cardiac arrest, and age $\geq 65 y$, time to the start of $C P R \geq 12 \mathrm{~min}$, unable to defibrillation, duration of $C P R \geq 40 \mathrm{~min}$, cumulative adrenaline dosage $\geq 6 \mathrm{mg}$ are the independent risk factors of CPR failure, clinical early alert and targeted preventions are needed for those patients to increase the success rate of CRP, to improve the prognosis of SCA patients. However, limited by sample size, future studies with larger sample size and multi-centers are needed for further confirmation on the influencing factors of PCR, to provide more reliable evidences to the management and treatment of SCA.

\section{Abbreviations}

CPR: cardiopulmonary resuscitation

SCA: sudden cardiac arrest

VT: ventricular tachycardia

VF: ventricular fibrillation

AHA: American Heart Association

\section{Declarations}

\section{Ethics approval and consent to participate}

In this study, all methods were performed in accordance with the relevant guidelines and regulations. This present study protocol had been checked and approved by the ethical committee of Hangzhou First People's Hospital(approval numb er:ED20180049M), and written informed consents had been obtained from the relatives of included patients.

\section{Consent for publication}

Not applicable.

\section{Availability of data and materials}

All data generated or analyzed during this study are included in this published article.

\section{Competing interests}

The authors declare that they have no competing interests. 


\section{Funding}

None.

\section{Author contributions}

L H, X M designed research; L H, J C, B Y, C T, X M conducted research; L H, J C analyzed data; X M wrote the first draft of manuscript; $\mathrm{X} M$ had primary responsibility for final content. All authors read and approved the final manuscript.

\section{Acknowledgments}

None.

\section{References}

1. Stiles MK, Wilde AAM, Abrams DJ, Ackerman MJ, Albert CM, Behr ER, Chugh SS, Cornel MC, Gardner $\mathrm{K}$, Ingles $\mathrm{J}$ et al: 2020 APHRS/HRS expert consensus statement on the investigation of decedents with sudden unexplained death and patients with sudden cardiac arrest, and of their families. Heart Rhythm 2021, 18(1):e1-e50.

2. Seelhammer T, Wittwer E: Survivorship After Sudden Cardiac Arrest: Establishing a Framework for Understanding and Care Optimization. J Cardiothorac Vasc Anesth 2021, 35(2):368-373.

3. Markwerth P, Bajanowski T, Tzimas I, Dettmeyer R: Sudden cardiac death-update. Int J Legal Med 2021, 135(2):483-495.

4. Aziz K, Lee CHC, Escobedo MB, Hoover AV, Kamath-Rayne BD, Kapadia VS, Magid DJ, Niermeyer S, Schmolzer GM, Szyld E et al: Part 5: Neonatal Resuscitation 2020 American Heart Association Guidelines for Cardiopulmonary Resuscitation and Emergency Cardiovascular Care. Pediatrics 2021, 147(Suppl 1).

5. Anez C, Becerra-Bolanos A, Vives-Lopez A, Rodriguez-Perez A: Cardiopulmonary Resuscitation in the Prone Position in the Operating Room or in the Intensive Care Unit: A Systematic Review. Anesth Analg 2021, 132(2):285-292.

6. Phan D, Clare R, Duan L, Kim C, Moore N, Lee MS: Characteristics and outcomes of patients with spontaneous coronary artery dissection who suffered sudden cardiac arrest. $J$ Interv Card Electrophysio/ 2021, 60(1):77-83.

7. Abdelazeem B, Gergis K, Baral N, Rauniyar R, Adhikari G: Sudden Cardiac Death and Sudden Cardiac Arrest in Patients with Human Immunodeficiency Virus: A Systematic Review. Cureus 2021, 13(3):e13764. 
8. Paratz ED, Rowsell L, van Heusden A, Zentner D, Parsons S, Morgan N, Thompson T, James P, Pflaumer A, Semsarian C et al: The End Unexplained Cardiac Death (EndUCD) Registry for Young Australian Sudden Cardiac Arrest. Heart Lung Circ 2021, 30(5):714-720.

9. SW J, BQ F, ZK H: Abdominal lifting and compression cardiopulmonary resuscitation for treatment of a 84-year old cardiac arrest patient Chin Crit Care Med 2017, 29(2):179-180.

10. Kim DK, Shin SD, Ro YS, Song KJ, Hong KJ, Joyce Kong SY: Place-provider-matrix of bystander cardiopulmonary resuscitation and outcomes of out-of-hospital cardiac arrest: A nationwide observational cross-sectional analysis. PLoS One 2020, 15(5):e0232999.

11. Panchal AR, Berg KM, Hirsch KG, Kudenchuk PJ, Del Rios M, Cabanas JG, Link MS, Kurz MC, Chan PS, Morley PT et al: 2019 American Heart Association Focused Update on Advanced Cardiovascular Life Support: Use of Advanced Airways, Vasopressors, and Extracorporeal Cardiopulmonary Resuscitation During Cardiac Arrest: An Update to the American Heart Association Guidelines for Cardiopulmonary Resuscitation and Emergency Cardiovascular Care. Circulation 2019, 140(24):e881-e894.

12. Soar J, Maconochie I, Wyckoff MH, Olasveengen TM, Singletary EM, Greif R, Aickin R, Bhanji F, Donnino MW, Mancini ME et al: 2019 International Consensus on Cardiopulmonary Resuscitation and Emergency Cardiovascular Care Science With Treatment Recommendations: Summary From the Basic Life Support; Advanced Life Support; Pediatric Life Support; Neonatal Life Support; Education, Implementation, and Teams; and First Aid Task Forces. Circulation 2019, 140(24):e826-e880.

13. Wong CX, Brown A, Lau DH, Chugh SS, Albert CM, Kalman JM, Sanders P: Epidemiology of Sudden Cardiac Death: Global and Regional Perspectives. Heart Lung Circ 2019, 28(1):6-14.

14. Rea TD, Crouthamel M, Eisenberg MS, Becker LJ, Lima AR: Temporal patterns in long-term survival after resuscitation from out-of-hospital cardiac arrest. Circulation 2003, 108(10):1196-1201.

15. Chan PS, McNally B, Tang F, Kellermann A, Group CS: Recent trends in survival from out-of-hospital cardiac arrest in the United States. Circulation 2014, 130(21):1876-1882.

16. Blom MT, Beesems SG, Homma PC, Zijlstra JA, Hulleman M, van Hoeijen DA, Bardai A, Tijssen JG, Tan HL, Koster RW: Improved survival after out-of-hospital cardiac arrest and use of automated external defibrillators. Circulation 2014, 130(21):1868-1875.

17. Perkins GD, Jacobs IG, Nadkarni VM, Berg RA, Bhanji F, Biarent D, Bossaert LL, Brett SJ, Chamberlain D, de Caen AR et al: Cardiac arrest and cardiopulmonary resuscitation outcome reports: update of the Utstein Resuscitation Registry Templates for Out-of-Hospital Cardiac Arrest: a statement for healthcare professionals from a task force of the International Liaison Committee on Resuscitation (American Heart Association, European Resuscitation Council, Australian and New Zealand Council on Resuscitation, Heart and Stroke Foundation of Canada, InterAmerican Heart Foundation, Resuscitation Council of Southern Africa, Resuscitation Council of Asia); and the American Heart Association Emergency Cardiovascular Care Committee and the Council on Cardiopulmonary, Critical Care, Perioperative and Resuscitation. Circulation 2015, 132(13):1286-1300. 
18. Speer T, Dersch W, Kleine B, Neuhaus C, Kill C: Mechanical Ventilation During Resuscitation: How Manual Chest Compressions Affect a Ventilator's Function. Adv Ther 2017, 34(10):2333-2344.

19. DeFroda SF, McDonald C, Myers C, Cruz Al, Owens BD, Daniels AH: Sudden Cardiac Death in the Adolescent Athlete: History, Diagnosis, and Prevention. Am J Med 2019, 132(12):1374-1380.

20. Harris AW, Kudenchuk PJ: Cardiopulmonary resuscitation: the science behind the hands. Heart 2018, 104(13):1056-1061.

21. Cone DC, Burns K, Maciejewski K, Dziura J, McNally B, Vellano K, Group CS: Sudden cardiac arrest survival in HEARTSafe communities. Resuscitation 2020, 146:13-18.

22. Strohle M, Vogele A, Neuhauser P, Rauch S, Brugger H, Paal P: Sudden Cardiac Arrest and Cardiopulmonary Resuscitation with Automated External Defibrillator in the Austrian Mountains: A Retrospective Study. High Alt Med Biol 2019, 20(4):392-398.

23. Nikolaou N, Dainty KN, Couper K, Morley P, Tijssen J, Vaillancourt C, International Liaison Committee on Resuscitation's Basic Life S, Pediatric Task F: A systematic review and meta-analysis of the effect of dispatcher-assisted CPR on outcomes from sudden cardiac arrest in adults and children. Resuscitation 2019, 138:82-105.

24. Serdyuk S, Davtyan K, Burd S, Drapkina O, Boytsov S, Gusev E, Topchyan A: Cardiac arrhythmias and sudden unexpected death in epilepsy: Results of long-term monitoring. Heart Rhythm 2021, 18(2):221-228.

25. Iwami T, Kitamura T, Kawamura T, Mitamura H, Nagao K, Takayama M, Seino $Y$, Tanaka H, Nonogi $H$, Yonemoto $\mathrm{N}$ et al: Chest compression-only cardiopulmonary resuscitation for out-of-hospital cardiac arrest with public-access defibrillation: a nationwide cohort study. Circulation 2012, 126(24):28442851.

26. Nakamura K, Funabashi N, Miyauchi H, Aminaka M, Uehara M, Ueda M, Murayama T, Hori Y, Nakayama T, Daimon $\mathrm{M}$ et al: Hemangioma located just above the left main coronary artery, in a subject who had cardiac arrest due to ventricular fibrillation, led to a diagnosis of Brugada syndrome. Int J Cardiol 2008, 127(3):437-441.

27. Jagosz A, Bursy D, Sobon A, Kiczmer P, Copik M, Bialka S, Smereka J, Misiolek H, Szarpak L: Inhospital sudden cardiac arrest protocol analysis. Kardiol Pol 2018, 76(2):376-380.

28. Wagner-Berger HG, Wenzel V, Stallinger A, Voelckel WG, Rheinberger K, Augenstein S, Herff H, Idris AH, Dorges $\mathrm{V}$, Lindner $\mathrm{KH}$ et al: Optimizing bag-valve-mask ventilation with a new mouth-to-bag resuscitator. Resuscitation 2003, 56(2):191-198.

29. von Goedecke A, Keller C, Wagner-Berger HG, Voelckel WG, Hormann C, Zecha-Stallinger A, Wenzel V: Developing a strategy to improve ventilation in an unprotected airway with a modified mouth-to-bag resuscitator in apneic patients. Anesth Analg 2004, 99(5):1516-1520; table of contents.

30. Newell C, Grier S, Soar J: Airway and ventilation management during cardiopulmonary resuscitation and after successful resuscitation. Crit Care 2018, 22(1):190.

31. Wen $\mathrm{C}, \mathrm{Yu}$ T, Wang L: [Progress of mechanical ventilation during cardiopulmonary resuscitation]. Zhonghua Wei Zhong Bing Ji Jiu Yi Xue 2017, 29(9):853-856. 
32. Johnson NJ, Carlbom DJ, Gaieski DF: Ventilator Management and Respiratory Care After Cardiac Arrest: Oxygenation, Ventilation, Infection, and Injury. Chest 2018, 153(6):1466-1477.

33. Wei Q, Xian W, Shifu D: Comparison of the effects of tracheal intubation and balloon assisted breathing in prehospital first aid for cardiac arrest. Internal Medicine 2018, 13(2):244-246.

34. Wei Z, Zhiwei X: Comparison of the effects of balloon and tracheal intubation assisted breathing in prehospital first aid for cardiac arrest. Journal of Clinical Pulmonology 2015, 20(2):349-350.

35. Andersen LW, Kurth T, Chase M, Berg KM, Cocchi MN, Callaway C, Donnino MW, American Heart Association's Get With The Guidelines-Resuscitation I: Early administration of epinephrine (adrenaline) in patients with cardiac arrest with initial shockable rhythm in hospital: propensity score matched analysis. BMJ 2016, 353:i1577.

36. Andersen LW, Berg KM, Saindon BZ, Massaro JM, Raymond TT, Berg RA, Nadkarni VM, Donnino MW, American Heart Association Get With the Guidelines-Resuscitation I: Time to Epinephrine and Survival After Pediatric In-Hospital Cardiac Arrest. JAMA 2015, 314(8):802-810.

37. Mavroudis CD, Ko TS, Morgan RW, Volk LE, Landis WP, Smood B, Xiao R, Hefti M, Boorady TW, Marquez $A$ et al: Epinephrine's effects on cerebrovascular and systemic hemodynamics during cardiopulmonary resuscitation. Crit Care 2020, 24(1):583.

38. Perkins GD, Kenna C, Ji C, Deakin CD, Nolan JP, Quinn T, Scomparin C, Fothergill R, Gunson I, Pocock $\mathrm{H}$ et al: The influence of time to adrenaline administration in the Paramedic 2 randomised controlled trial. Intensive Care Med 2020, 46(3):426-436.

\section{Figures}




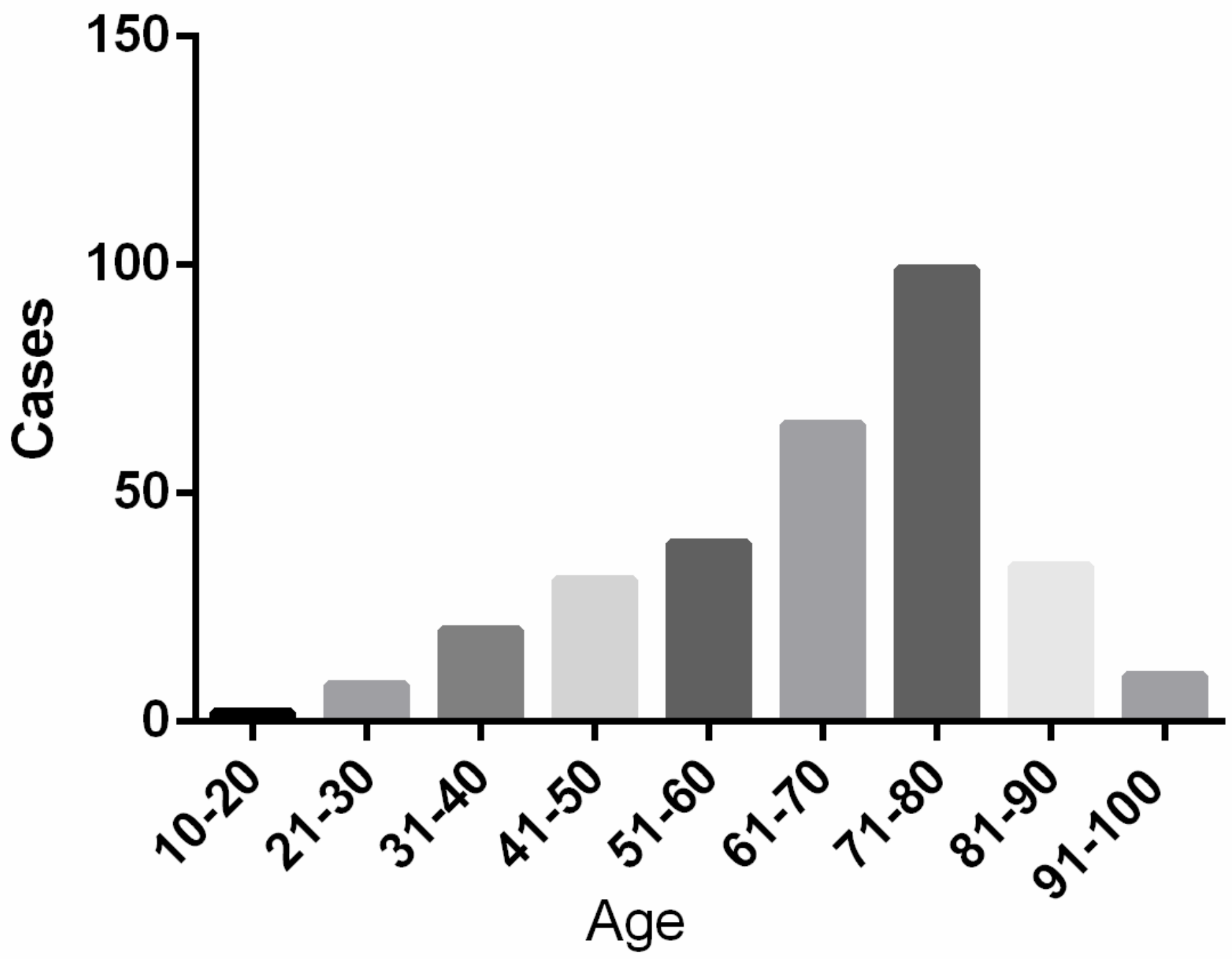

Figure 1

Age distribution of patients with CPR

\section{Supplementary Files}

This is a list of supplementary files associated with this preprint. Click to download.

- STROBEchecklist.docx 